\title{
Economics at the FCC 2019-2020: Spectrum Policy, Universal Service, Inmate Calling Services, and Telehealth
}

\author{
Allison Baker ${ }^{2} \cdot$ Patrick Brogan ${ }^{2} \cdot$ Octavian Carare $^{2} \cdot$ Nicholas Copeland $^{2}$. \\ Patrick DeGraba ${ }^{2}$. Steven Kauffman ${ }^{2}$. Paul Lafontaine ${ }^{2}$. Catherine Matraves ${ }^{2}$. \\ Jeffrey Prince ${ }^{1,2}$ D Sean Sullivan ${ }^{2} \cdot$ Patrick Sun $^{2} \cdot$ Emily Talaga $^{2}$
}

Accepted: 6 October 2020 / Published online: 23 October 2020

(c) Springer Science+Business Media, LLC, part of Springer Nature 2020

\begin{abstract}
The U.S. Federal Communications Commission is responsible for regulation in the communications marketplace and for management of the nation's non-federal radio frequency spectrum. During the past year, FCC economists helped develop efficient mechanisms for making available more flexible-use spectrum for the deployment of advanced broadband technologies; developed two new universal service funding mechanisms that aim to close the digital broadband divide; and, through careful analysis of firm cost data, contributed to a renewed effort by the Commission to develop price caps for interstate calls on prison inmate calling services. FCC economists also contributed to the Commission's extensive response to COVID-19.
\end{abstract}

Keywords FCC $\cdot$ Telecommunications policy $\cdot$ Spectrum policy $\cdot$ Universal service . Rural digital opportunity fund $\cdot 5 \mathrm{G}$ fund $\cdot$ Inmate calling services $\cdot$ COVID-19 and telehealth

\section{Introduction}

The U.S. Federal Communications Commission (FCC) is an independent regulatory agency with responsibility for the telecommunications and electronic media sectors, including the allocation and management of all non-federal U.S. radio frequency spectrum. For fiscal years 2018-2022, the FCC revised its strategic goals around four priorities: closing the digital divide; promoting innovation; protecting consumers and public safety; and reforming the FCC's processes (FCC 2017a, p. 4). ${ }^{1}$

\footnotetext{
${ }^{1}$ FCC initiatives include Keep Americans Connected, Bridging the Digital Divide for all Americans, and the FCC's 5G FAST Plan, available at https://www.fcc.gov/about-fcc/fcc-initiatives.
}

Jeffrey Prince

jeffprin@indiana.edu

Extended author information available on the last page of the article 
FCC economists contribute to the realization of each of these goals, and this article highlights some of the more interesting economic analyses that were carried out over the past year. Section 2 outlines recent proceedings-including the 3.7-4.2 GHz (C-Band) (FCC 2020a) and the 2.5 GHz band (FCC 2019a) proceedings - to make available more flexible-use spectrum ${ }^{2}$ to meet the ever-increasing demand for wireless services. ${ }^{3}$

Section 3 explains the analyses that were undertaken with respect to the Rural Digital Opportunity Fund and the proposed 5G Fund for Rural America. These two new universal service funds will help ensure that all Americans-no matter where they live-have access to advanced communications capabilities (FCC 2020b, c, d). With respect to the proposed 5G Fund, we explain how empirical analysis of service provider entry behavior, infrastructure deployment, and bidding behavior were used to help determine the relative costs and benefits of deploying mobile broadband services across high-cost rural areas (FCC 2020e).

Section 4 discusses the economic analysis conducted by FCC economists on firm cost data to inform proposed price caps for prison inmate calling services (ICS). Lastly, Sect. 5 highlights actions that have been taken by the FCC in response to COVID-19 that were informed by FCC economists.

\section{Spectrum Policy}

The provision of mobile wireless service requires a combination of inputs. These include: spectrum; cellular base stations; radio equipment to transmit signals between base stations and end user devices; and backhaul facilities to route voice and data traffic from the base stations to the core network. Spectrum is an essential input for wireless services: It allows for wireless communication between handsets and physical infrastructure. Access to additional spectrum is critical to reducing the cost of mobile services for entrants that are deploying service in a new geographic area, as well as for existing service providers that are expanding capacity (FCC 2018a, p. 12584).

The FCC has primary responsibility for managing all commercial and other nonfederal spectrum. The FCC's two broad goals in this task are: (i) to promote competition in the marketplace of spectrum-based services; and (ii) to encourage the efficient and intensive use of spectrum. The FCC has a number of tools to achieve

\footnotetext{
${ }^{2}$ Flexible-use spectrum allows the licensee to choose which services and technologies to deploy in a band within specified power and interference limits and relies on the market to shift uses as technology and user tastes change. In contrast, historically the regulator defined the specific permitted services in each band (e.g., broadcasting) and reallocated spectrum through an administrative process as new uses arose (FCC 2018a, n. 882).

${ }^{3}$ For example, Ericsson predicts that total mobile traffic is expected to increase by a factor of five over the next six years, reaching 131 exabytes per month by the end of 2024. Ericsson further predicts that, in 2024, traffic generated by smartphones is projected to be $95 \%$ of total mobile data traffic and 5G networks will carry a quarter of all global mobile data traffic. See Ericsson, Mobility Report (2019) https ://www.ericsson.com/49d1d9/assets/local/mobility-report/documents/2019/ericsson-mobility-repor t-june-2019.pdf.
} 
the second goal, including allocating or reallocating spectrum to higher-valued uses, assigning buildout requirements with licenses, promulgating rules that facilitate spectrum sharing, and assigning previously unassigned frequencies (FCC 2018a, pp. 12714-12715).

The FCC's priority of making available more flexible-use spectrum is crucial for the country's rapid deployment of $5 \mathrm{G}$ networks. ${ }^{4} 5 \mathrm{G}$ promises to bring significantly faster speeds and lower latency, which is the basis for a number of promising innovative services, such as high-definition telemedicine, the Internet of Things (IoT), ${ }^{5}$ and precision agriculture. "Mid-band" frequency spectrum is critical for 5G deployment due to its desirable combination of coverage, capacity, and propagation characteristics (FCC 2020a, p. 2345). ${ }^{7}$ In this section, we discuss the $3.7-4.2 \mathrm{GHz}$ proceeding (C-band) and the $2.5 \mathrm{GHz}$ proceeding. We also provide a brief summary of the recently concluded millimeter-wave $(\mathrm{mmW})$ spectrum auctions.

\subsection{C-Band Proceeding}

Fixed Satellite Service (FSS) operators today use the 500 megahertz of spectrum in the 3.7-4.2 GHz band (C-Band) primarily to deliver programming to television and radio broadcasters throughout the country and to provide some telephone and data services to consumers (FCC 2020a, p. 2347). ${ }^{8}$

In this proceeding, the FCC established a process to make the lower $300 \mathrm{meg}$ ahertz of spectrum available for flexible use (FCC 2020a). Nearly all of the incumbent FSS operations would be relocated from the lower 300 megahertz (3.7 GHz-4.0 GHz) into the upper 200 megahertz of the band (4.0-4.2 GHz) (FCC 2020a, p. 2396). The FCC also adopted an auction of flexible use overlay licenses ${ }^{9}$ to distribute the terrestrial flexible use rights (FCC 2020a, p. 2353). ${ }^{10}$ The winning

\footnotetext{
4 " $5 \mathrm{G}$ is the 5 th generation mobile network[]... designed to connect everyone and everything together including machines, objects and devices." $5 \mathrm{G}$ will produce higher speed, lower latency, and greater reliability than have previous technology generations. See Everything you need to know about $5 \mathrm{G}$, available at https://www.qualcomm.com/invention/5g/what-is-5g.

${ }^{5}$ IoT refers to the billions of physical devices that are now connected to the internet: collecting and sharing data. See What is IoT, available at https://www.zdnet.com/article/what-is-the-internet-of-things-every thing-you-need-to-know-about-the-iot-right-now/.

${ }^{6}$ See Chairman Pai video, available at https://www.fcc.gov/5G.

${ }^{7}$ Low-frequency spectrum (below $1 \mathrm{GHz}$ ) has better propagation than mid band spectrum (between 1 and $6 \mathrm{GHz}$ ) but has lower capacity and therefore will have lower download speeds. Higher band spectrum has higher capacity and therefore higher download speeds, but much shorter propagation distances. Millimeter wave spectrum is defined as frequencies at $24 \mathrm{GHz}$ or higher.

${ }^{8}$ The 3.7-4.2 GHz band is also used for reception of telemetry signals that are transmitted from satellites to earth stations (FCC 2020a, p. 2348). In addition, the C-Band is used for terrestrial fixed point-topoint service, which will be phased out following the clearing process that will be described below.

${ }^{9}$ With overlay licenses, the licensees obtain the rights to geographic area licenses "overlaid" on top of the incumbent licensees, meaning that they may operate anywhere within its geographic area, subject to protecting the operations of incumbent licensees (FCC 2020a, p. 2354) and complying with any other obligations.

${ }^{10}$ These 300 megahertz will be divided into fourteen 20 megahertz blocks for terrestrial flexible use and exclusive rights to use along with a 20-megahertz guard band (FCC 2020a, p. 2377). These blocks would
} 
overlay licensees are required to pay all reasonable relocation costs that are associated with satellite operators' relocating their traffic to the upper 200 megahertz. ${ }^{11}$

The order also adopts an accelerated relocation timeline and payment system. While satellite operators could have taken until September 30, 2025, to clear the lower 300 megahertz for terrestrial use, the order gave the operators the option of agreeing to an accelerated clearing timeline (FCC 2020a, p. 2454). As of today, all five satellite operators have elected accelerated relocation. ${ }^{12}$ By agreeing to clear the spectrum sooner, satellite operators have set the stage to create significant value for the new flexible-use licensees by allowing them to deploy services sooner. Phase I accelerated relocation requires satellite operators to clear the lowest 120 megahertz (3.7-3.82 GHz) by December 5, 2021, and Phase II requires clearing the remaining 180 megahertz (3.82-4.0 GHz) by December 5, 2023 (FCC 2020a, pp. 2413-2414).

Satellite operators that meet these deadlines will receive a portion of the value that is created by freeing up the spectrum for licensees sooner through accelerated relocation payments from flexible-use licensees. Payments will total $\$ 9.7$ billion if all five operators meet all deadlines (FCC 2020a, p. 2438). ${ }^{13}$ A satellite operator that misses either the Phase I or Phase II clearing deadline will receive less than the portion of the accelerated relocation payment that is attributable to the deadline that it missed-depending on how late it completes its clearing obligation. (FCC 2020a, p. 2414).

The C-band presented unique reallocation challenges largely because of the shared spectrum rights of the satellite operators. Specifically, each satellite operator has the right to transmit in the entire $3.7-4.2 \mathrm{GHz}$ range without harmful interference (FCC 2020a, p. 2366, p. 2404). Since each operator has the right to continue to use the entire band, all five must clear the band in order to make the spectrum available for alternative uses. A related issue is that, once all earth stations have been cleared in a given geographic area, the spectrum could be used by all terrestrial licensees in that area (FCC 2020a, p. 2418). Since relocation is costly, and new licensees are required to cover these costs, each new licensee has a "free rider" incentive to wait for other licensees in the area to cover the relocation costs.

This structure of shared spectrum rights among satellite operator licensees, and shared benefits among flexible use licensees from clearing, suggest that bilateral private market transactions would not be likely to succeed in transferring rights from satellite operators to terrestrial use. Even in the absence of regulatory frictions

\footnotetext{
Footnote 10 (continued)

be auctioned in geographic areas known as a partial economic areas (PEAs). There are 416 PEAs in the US. https://www.fcc.gov/oet/maps/areas.

11 These costs will include the costs that are incurred by satellite operators, such as launching new satellites and reallocating terrestrial earth stations to different satellites, as well as the costs of fitting the earth stations with new compression, modulation and/or passband filter equipment and retuning the satellite dishes (FCC 2020a, pp. 2424-2425).

12 Operators that represent $80 \%$ of U.S. C-band satellite traffic had to commit to accelerated relocation for the timeline to be adopted. See C-Band Spectrum Will be Made Available for 5G Services on an Accelerated Basis, available at https://docs.fcc.gov/public/attachments/DOC-364655A1.pdf.

13 The $\$ 9.7$ billion total is substantially lower than the total amount we estimate that overlay licensees themselves would be willing to spend to clear this spectrum early (FCC 2020a, p. 2438).
} 
such as licensing and new service rules, since each satellite operator has the right to transmit in the entire band, one satellite operator could not sell a potential flexible use licensee the exclusive right to operate in an area through a bilateral transaction. Specifically, while the satellite operator could divest its own non-interference rights, it could not ensure that other operators would not enforce their spectrum rights. ${ }^{14}$

Similarly, bilateral (or even multilateral) market transactions that would result in flexible use licensees. agreeing to pay the cost of clearing earth stations may be difficult to achieve. A licensee would be reluctant to commit to cover a portion of the costs of relocating an earth station's frequency unless it knew that the other licensees would pay their "fair share" of relocation costs. Additionally, if multiple earth stations had to be cleared before spectrum could be used, a licensee would need to know that the other licensees would pay their share of the relocation costs for all earth stations.

The solution that was adopted by the FCC was designed to overcome both the collective action and the free-rider problems that are created by the shared rights of the satellite operators and the shared benefits among licensees of the clearing process. First, the FCC auction of new flexible use licenses will give licensees the exclusive rights to use the spectrum that they win in the auction, once clearing in an area allows them to operate without interfering with satellite transmissions, ${ }^{15}$ which will be no later than December 2025 (FCC 2020a, p. 2408).

Second, by participating in the auction, licensees agree to make payments according to the established, single market-wide accelerated relocation schedule (FCC 2020a, p. 2415), which mitigates the licensees' problem of not being able to pay for accelerated clearing by one satellite operator for fear that it would be rendered useless by another operator's not clearing early. ${ }^{16}$

Third, requiring bidders to agree to make defined earth station relocation cost payments and accelerated relocation satellite operator payments based on their pro rata shares of gross winning bids as a condition of entering the auction (FCC 2020a, p. 2445) eliminated the free-rider problem among licensees.

Additionally, the reallocation framework-particularly the accelerated relocation option-relied on voluntary decisions by participants, to ensure that transactions are Pareto-improving. For example, by having satellite operators opt into the early clearing schedule, the FCC can be sure that the accelerated relocation payments will cover the costs of the satellite operators of accelerated relocation. Similarly, by having bidders agree to the well-specified relocation-cost payment schedules as a

\footnotetext{
14 The C-Band Alliance had proposed to sell the rights of all five satellite operators in a single block, which would "solve" the problem of licensees not obtaining exclusive rights, but would create a new problem of a monopolist selling spectrum rights, or as the Commission stated, "...vesting private entities with the exclusive ability to allocate new terrestrial rights..." “... lacks..." "...the procompetitive features of a public auction..." (FCC 2020a, p. 2362).

15 And the licensees must have complied with all obligations to reimburse relocation and accelerated relocation costs (FCC 2020a, p. 2386).

16 Of course solving the contractual problem does not eliminate the possibility that a satellite owner fails to clear spectrum on time for reasons beyond its control or unforeseen circumstances.
} 
condition of participating in the auction, one would expect that the benefits to the winners will exceed the relocation costs that they will cover.

\subsection{GHz Proceeding}

The $2.5 \mathrm{GHz}$ band is the single largest band of contiguous spectrum below 3 gigahertz, and much of it has lain fallow for more than 20 years (FCC 2019a, p. 5447). Similar to the C-Band spectrum, it is mid-band spectrum that "offers favorable characteristics for enabling wireless networks to achieve coverage and capacity." (FCC 2019a, p. 5447). In 2019 the FCC revised its rules to provide more flexibility in how the spectrum can be used, and created opportunities for access to unused $2.5 \mathrm{GHz}$ spectrum (FCC 2019a, p. 5447).

Specifically, prior to the recent changes, only particular educational entities were eligible to hold an Educational Broadband Service license, ${ }^{17}$ and they were allowed to lease their excess capacity to commercial entities as long as they reserved a minimum of $5 \%$ of their spectrum capacity and ensured a minimum of $20 \mathrm{~h}$ a week of educational use (per channel) by accredited educational institutions (FCC 2019a, p. 5448). However, much of the licensed spectrum remains unassigned in a large portion of the United States, especially in rural areas west of the Mississippi (FCC 2019a, p. 5449).

In order to facilitate the most efficient use of the $2.5 \mathrm{GHz}$ band through a market-based mechanism, eligibility requirements for licensees were eliminated. This allows $2.5 \mathrm{GHz}$ licensees to assign or transfer their licenses freely to any entity (FCC 2019a, p. 5451). In addition, to provide more flexible use, the educational use requirements were eliminated (FCC 2019a, p. 5450). The educational use requirements were based on the use of video in 1998; given the dramatic change in circumstances, the FCC concluded that it is now more efficient to allow licensees flexibility to use the spectrum the way that the licensees want rather than maintaining outdated requirements (FCC 2019a, p. 5456).

Finally, the FCC adopted an auction of overlay licenses for all currently unlicensed spectrum; the Commission concluded that "offering geographic overlay licenses that are subject to competitive bidding in those markets where white spaces (i.e., spectrum that is not associated with an active license) exist is the best mechanism for assigning this spectrum." (FCC 2019a, p. 5473). ${ }^{18}$ Since the overlay licensee may operate anywhere within its geographic license area subject to protecting the incumbent services, the assignment of overlay licenses maximizes the potential use of the spectrum without disrupting incumbents (FCC 2019a, p. 5473).

\footnotetext{
17 These entities are: (1) accredited public and private education institutions; (2) governmental organizations that are engaged in the formal education of enrolled students; and (3) nonprofit organizations whose purpose is educational.

18 A Rural Tribal Priority Window was adopted for Tribal entities to obtain $2.5 \mathrm{GHz}$ licenses on Tribal lands in rural areas prior to the commercial auction (FCC 2019, p. 5463).
} 


\section{$2.3 \mathrm{mmW}$ Spectrum Auctions}

Millimeter wave frequencies ( $\mathrm{mmW}$ )—which are designated as $24 \mathrm{GHz}$ and above-had historically been considered unsuitable for fixed and mobile wireless services due to limited signal propagation at such high frequencies and the inability of $\mathrm{mmW}$ signals to penetrate through obstacles, especially buildings. However, technological advances are making it possible that $\mathrm{mmW}$ spectrum could support fixed and mobile wireless services. In a series of three orders, the FCC adopted rules to facilitate flexible terrestrial wireless use of 4,950 megahertz of $\mathrm{mmW}$ spectrum across the $24 \mathrm{GHz}, 28 \mathrm{GHz}, 37 \mathrm{GHz}, 39 \mathrm{GHz}$, and $47 \mathrm{GHz}$ bands. Each of these three bands will be licensed in multiple blocks of different sizes and geographic areas (FCC 2016a, 2017b, 2018b).

The $28 \mathrm{GHz}$ auction in 2018 (Auction 101) and the $24 \mathrm{GHz}$ auction in 2019 (Auction 102) together made 1550 megahertz of mmW spectrum-ideal for lowlatency, high-capacity operations-available for commercial use (FCC 2019b, c) ${ }^{19}$ In addition, in 2018, the FCC established only its second incentive auction (Auction 103) to clear existing licenses in the $39 \mathrm{GHz}$ band and offer 3,400 megahertz of new spectrum licenses in the Upper $37 \mathrm{GHz}, 39 \mathrm{GHz}$, and $47 \mathrm{GHz}$ bands (FCC 2018c). The incentive auction cleared existing $39 \mathrm{GHz}$ licenses by offering incumbent licensees the opportunity to relinquish existing rights for a payment that is determined by the auction ${ }^{20}$ and offered new spectrum licenses in the Upper $37 \mathrm{GHz}, 39 \mathrm{GHz}$, and $47 \mathrm{GHz}$ bands (FCC 2018c). Auction 103 closed in March 2020, with 28 bidders winning a total of 14,142 licenses (FCC 2020g). ${ }^{21}$ These three auctions together made available almost five gigahertz of high-band spectrum for commercial usemore than all other flexible use bands combined. ${ }^{22}$

\footnotetext{
19 Auction 101 raised (in gross bids) a total of $\$ 702,572,410$ with a total of 2,965 licenses won (FCC 2019 b). Auction 102 raised a total of $\$ 2,022,676,752$ in net bids $(\$ 2,024,268,941$ in gross bids), with 29 bidders' winning a total of 2,904 licenses (FCC 2019c).

${ }^{20}$ We note that incumbent licensees could also choose to replace existing licenses for new licenses for whole blocks that would be assigned contiguous frequencies within license areas. In addition, if licensees chose not to participate, their licenses would be modified for contiguous 100-megahertz blocks that covered full "partial economic areas" (PEAs) (FCC 2018c).

21 Auction 103 raised a total of $\$ 7,558,703,201$ in net bids $(\$ 7,569,983,122$ in gross bids). Based on these bids, the incentive payments for existing licensees total $\$ 3,084,172,898$, and the net proceeds for the auction total \$4,474,530,303 (FCC 2020g).

${ }^{22}$ For context, the FCC's spectrum screen, which includes low-band and mid-band spectrum, and is utilized in the FCC's review of proposed secondary market transactions, currently totals 743 megahertz. In its analysis of proposed secondary market transactions, the FCC uses an initial spectrum screen as an analytical tool to help identify for case-by-case review those local markets where changes in spectrum holdings as a result of the transaction may raise competitive concerns.
} 


\section{Universal Service: Rural Digital Opportunity Fund and the 5G Fund}

In this section, we discuss two new universal service mechanisms whose primary goal is to make sure that all Americans, no matter where they live and work, have access to reliable advanced broadband comparable to urban areas. The Rural Digital Opportunity Fund will provide up to $\$ 20.4$ billion, in two phases, to connect millions of unserved rural homes and small businesses to fixed high-speed broadband networks (FCC 2020c, p. 2). The 5G Fund will provide up to $\$ 9$ billion, in two phases, to bring mobile wireless voice and $5 \mathrm{G}$ broadband to rural areas that would otherwise be unlikely to see unsubsidized deployment (FCC 2020d, p. 3).

\subsection{Rural Digital Opportunity Fund}

The Rural Digital Opportunity Fund is the next major step in the FCC's ongoing efforts to introduce more economically efficient funding mechanisms into the distribution of universal service support. It will use a two-phase reverse auction mechanism to subsidize the connection of up to 5.4 million unserved American homes and businesses in areas that are likely unprofitable to serve absent subsidies (FCC 2020c, p. 3; FCC 2020o). The Phase I auction will target those census blocks that are entirely unserved by voice and broadband networks that are capable of speeds of at least 25/3 Mbps (FCC 2020c, p. 3). Phase II will cover locations in census blocks that are partially served at this speed threshold, as well as locations that are not funded in Phase I (FCC 2020c, p. 3).

As background, in 2011, the FCC adopted a new universal service funding approach in areas that are served by the incumbent local exchange providers-which are known as "price cap areas" - through a combination of a forward-looking cost model and a competitive bidding process (FCC 2011). In 2015, the FCC allowed the incumbent price-cap providers to accept a "model-based" support amount as estimated by the Connect America Cost Model (CAM) in exchange for deploying 10/1 Mbps broadband in unserved areas. This process resulted in nine price cap providers accepting over $\$ 1.5$ billion in annual support to deploy to more than 3.6 million homes and businesses by the end of $2020 .^{23}$

In unserved areas where the price-cap providers declined the model-based support, support was allocated through a reverse auction of subsidies in 2018, which resulted in 103 winning bidders, with the 10-year support amount totaling almost $\$ 1.49$ billion (FCC 2018d, p. 1). Notably, the final auction price per location served was significantly lower than predicted by the CAM-which provides evidence that auctions can lead to substantial efficiency gains relative to administratively determined support amounts.

The Rural Digital Opportunity Fund auction will increase the minimum supported speed from 10/1 to 25/3 Mbps, will prioritize lower latency and higher speed

\footnotetext{
${ }^{23}$ FCC News Release, August 27, 2015, https://www.fcc.gov/document/carriers-accept-over-15-b-suppo rt-expandrural-broadband.
} 
broadband networks of up to a gigabit per second, and award support to the bidder that offers to provide the best combination of speed in latency in an area once the aggregate bidding price falls below the auction's budget (FCC 2020c, p. 3). Phase I of the auction is currently scheduled to begin on October 29, 2020 and will target locations in census blocks that lack access to 25/3 Mbps fixed broadband networks according to current FCC broadband mapping data (FCC 2020c, p. 5; FCC 2020f). When more granular mapping data become available, Phase II will cover Census blocks where only some of the locations have access to 25/3 Mbps speeds, as well as Census blocks that did not receive funding in Phase I (FCC 2020c, p. 5).

The Rural Digital Opportunity Fund auction will use many of the same rules and procedures that proved successful in the previous auction. As before, a descending clock auction will be used to identify the providers that will be assigned to receive support and to establish the support amount for each area (FCC 2020c, pp. 9-10). The auction will proceed by first setting reserve prices for each eligible Census block based on the previously developed cost model (FCC 2020c, p. 11). All bids will then be scored relative to this reserve price by calculating the bid amount as a percentage of the reserve amount. The clock will announce the current percentage of the reserve amount, and bidders can choose to submit a bid at the current clock percentage or an "exit bid" that is a percentage of the reserve price that is greater than the current clock price but less than or equal to the clock price in the previous round (FCC 2020f). Bids will be accepted for four performance tiers with varying speed and usage allowances and, for each performance tier, at either high or low latency for a total of eight possible performance categories (FCC 2020c, pp. 38-39).

Each bidding category is assigned a weight that is based on its combination of performance characteristics, with lower performing networks receiving larger weights (FCC 2020c, pp. 38-39). To determine the subsidy amount a bidder is eligible to receive at a given clock percentage, these weights would be subtracted from the clock percentage to arrive at an adjusted percentage of the reserve price for the area. No bidder will be eligible to receive more than the reserve price for an area, even though the clock percentage may exceed $100 \%$ (FCC 2020f). ${ }^{24}$ For example, a low latency gigabit speed bid has a weight of zero, while a low latency bid at the minimum speed of 25/3 Mbps would receive a weight of 50. Therefore, at a clock price of $75 \%$ of the reserve price in an area, the gigabit bidder would receive an annual support amount equal to the clock price percentage of the reserve amount, while the $25 / 3 \mathrm{Mbps}$ bidder would receive $25 \%$ of the reserve amount.

One notable difference between the 2018 auction and the Rural Digital Opportunity Fund is that the FCC has decided to favor higher performance networks once the auction budget has cleared-when the total support amount that is requested is less than or equal to the auction budget - and the auction system begins to assign winning bids (FCC 2020f, p. 228). In the budget clearing round, among bids for the same area at the same clock percentage, the bid for the highest performing network

\footnotetext{
24 The formula for the annual support amount that is implied at the clock percentage is: $\min \left\{\mathrm{R},\left(\frac{C-(T+L)}{100}\right) R\right\}$, where $\mathrm{R}$ is the reserve price, $\mathrm{C}$ is the clock price, $\mathrm{T}$ is the weight assigned to the particular speed tier, and $\mathrm{L}$ is the latency tier weight.
} 
will be assigned. In the 2018 auction, by contrast, bids for the same area tied at a percentage would have continued to compete at lower clock percentages. (FCC 2020c, p. 20). This decision was made to encourage "the deployment of networks that will be sustainable even as new advancements are made, and which will be capable of delivering the best level of broadband access for many years to come." (FCC 2020c, p. 11).

\subsection{The 5G Fund}

The rapid deployment of 5G in the United States is important for many reasons. 5G networks are expected to enhance mobile broadband performance greatly by increasing speeds and reducing latency, as well as enabling transformative new services that require robust wireless connectivity such as smart grids, Internet of Things, Virtual/Augmented Reality, precision agriculture, and a host of other services that have the potential to reshape many facets of American life (FCC 2020c, pp. 7-8). 5G mobile wireless broadband service is expected to create as many as three million new jobs, generate $\$ 275$ billion in private investment, and add $\$ 500$ billion in new economic growth. ${ }^{25}$ The FCC proposed to establish a 5G Fund for Rural America to help ensure that all Americans enjoy the benefits of the most modern, advanced communications technologies that are offered in the marketplace (FCC 2020d, p. 3). ${ }^{26}$

As part of the proposed 5G Fund auction design, the FCC proposed to incorporate a bid adjustment factor that would reflect the costs and benefits of deploying $5 \mathrm{G}$ in each geographic area. ${ }^{27}$ This would be done by assigning a weight to each geographic area that is based on the relative cost of serving areas with differing terrain characteristics and the potential business case for deploying a network in each area (FCC 2020d, pp. 22-23). The adjustment factor would aim to "level the playing field" for bidders that seek to serve geographic areas that were relatively more costly and to ensure that all Americans could potentially have access to 5G. The

\footnotetext{
25 See Accenture Strategy, Smart Cities How 5 G Can Help Municipalities Become Vibrant Smart Cities, https://newsroom.accenture.com/content/1101/files/Accenture_5G-Municipalities-Become-Smart-Citie s.pdf (last visited June 18, 2020).

26 The FCC noted its concern that "rural areas will remain where there is insufficient financial incentive for mobile wireless carriers to invest in 5G-capable networks, and those communities could be excluded from the technological and economic benefits of $5 \mathrm{G}$ for years to come. During this transition to $5 \mathrm{G}$ service, we therefore reaffirm our commitment to using Universal Service Fund support to close the digital divide and to make sure that parts of rural America are not left behind." (FCC 2020d, pp. 2-3).

27 The overall auction format is one in which a uniform support rate is offered across all eligible areas, and carriers indicate which specific areas they would serve at that rate. If the sum of all of the payments that would be made at a specific rate given carriers' expressed willingness to serve exceeds the 5G Fund budget, then the rate is lowered and carriers express their willingness to serve at the lower rate. This process continues until the payment is equal to the $5 \mathrm{G}$ Fund budget. Under this process, carriers will be willing to serve fewer areas as the rate falls, but if the same rate is offered for all remaining areas, more support than is needed will flow to the less costly-to-serve and more profitable remaining areas. The adjustment factor will, however, for any given support rate, allocate a multiple of the support rate to more costly and less profitable areas, thereby making them more attractive to serve and increasing the support to such areas.
} 
three economic analyses that are summarized below informed the FCC's proposed adjustment factor values (FCC 2020e, Appx. B, p. 1). ${ }^{28}$

\subsubsection{Entry Model and the Adjustment Factor}

The first approach uses third-party coverage data to understand how the characteristics of a geographic area drive a service provider's decision to deploy a mobile broadband network in a rural area (FCC 2020e, Appx. B, p. 1): We estimate an entry model that assumes that as a market becomes more attractive to providers, it will be able to support a greater number of entrants (Bresnahan and Reiss 1991). To understand what drives the attractiveness of any given area, we consider demographic and physical characteristics that could reasonably proxy for demand for wireless services and the costs of deploying service (FCC 2020e, Appx. B, p. 1). We use a latent variable framework where an area's attractiveness to providers is determined by these characteristics, and the number of providers providing service is, in turn, determined by the latent attractiveness value (FCC 2020e, Appx. B, p. 3). To understand if and how each variable affects the attractiveness of a geographic area, we estimate the following ordered logit model specification for the number of entrants in a census block group $^{29}$ :

$$
\begin{aligned}
\text { Attractiveness }_{i}= & \beta_{0}+\beta_{1} \text { Population Density }_{i}+\beta_{2} \text { Road Density }_{i}+\beta_{3} \text { GDP Density }_{i} \\
& +\gamma_{1} \log \left(\text { Income }_{i}\right)+\gamma_{2} \text { Dense Clutter }_{i}+\phi_{U S F_{i}}+f_{\text {terrain }}\left(\text { Terrain }_{i}\right)+\varepsilon_{i}
\end{aligned}
$$

Population, road miles, and local GDP enter the attractiveness equation on a per square-mile basis to account for differences in block group land areas. In addition to the density variables, we also include median household income as a proxy for wireless demand. Similarly, we include terrain roughness, the percentage of land covered by dense clutter, and a set of dummy variables that indicate the number and type of service providers that receive universal service support to proxy for deployment costs (FCC 2020e, Appx. B, pp. 3-4). Since the relationship between terrain roughness and signal propagation may be nonlinear, it is ex-ante unclear how this relationship translates into the profit function (FCC 2020e, Appx. B, p. 4). To allow for additional flexibility, we estimate the effect of terrain roughness using a piecewise linear spline.

The 5G Fund is focused on incentivizing network deployment in rural areas. To reflect this goal, the estimation sample is limited to block groups that the Census designates as at least $50 \%$ rural by land area and have population densities less than

\footnotetext{
${ }_{28}$ Given the constraints on length, we provide a short summary in this essay. For a more detailed discussion, we refer the reader to the Adjustment Factor Public Notice (FCC 2020e).

29 As a robustness check, we estimate an alternative binary choice model where the dependent variable is simply a dummy variable for whether an area is covered by any carrier. However, the additional information that is conveyed by the number of entrants is valuable when estimating block group attractiveness.
} 
100 persons per square mile. ${ }^{30}$ By restricting the sample, we are able to: i) focus on areas which are reasonably similar to potential eligible areas in the auction; and ii) avoid densely populated areas where providers' network deployment decisions are more likely to be determined by customer usage rather than by signal propagation limitations that are due to terrain. In total, we estimate 12 specifications of the model with the use of alternative attractiveness equations and dataset restrictions (FCC 2020e, Appx. B, p. 5). The results from the main specification of the model are displayed in Table 1 and Fig. 1 below.

Using the estimates from the ordered logit, we then calculate the demand scaling weights that are necessary to make the areas equally attractive to prospective entrants, and we set each area's probability of being served equal across geographic areas that differ in median household income and terrain, while holding all other factors that determine attractiveness fixed (FCC 2020e, Appx. B, p. 4). The weights we solve for indicate how much one would need to scale up a relatively "unattractive" area's demand characteristics to make its demand/cost ratio as attractive to enter. Hence, at a single per-square kilometer support rate, we effectively implement this "scaling up" of demand by instead "scaling up" the support rate with the use of the weights.

As is shown in Table 2, we find that rural areas with mountainous terrain require roughly 3.6 times the level of key demand characteristics of flat areas with otherwise identical characteristics to be equally attractive to providers in an auction. Similarly, areas with low median household income require a multiplier of roughly $1.3 \mathrm{com}$ pared to high income areas (FCC 2020e, Appx. B, p. 6).

\subsubsection{Cell Site Density Model and the Adjustment Factor Cell Site Density Model and the Adjustment Factor}

The second approach examines the relationship between terrain and the number of cell sites that a mobile wireless provider would need to build in order to serve a given geographic area at a fixed service quality (e.g., speed) (FCC 2020e, Appx. B, p. 11). All else being equal, wireless network engineering principles indicate that greater variability of terrain reduces the signal strength that is received by a mobile user, and therefore, more cell sites must be built closer together to provide the same quality of service when terrain is rougher (Jakes 1993; Rappaport 2002; Campbell Scientific 2016). If the cost of building a site is the same across terrain types, the number of additional cell sites is a direct measure of how much more costly it is to build mobile networks in more rugged terrain (FCC 2020e, Appx. B, p. 12). ${ }^{31}$

We estimate a regression model that uses county-level cell site counts and mobile coverage data for each of the four largest national mobile providers in the U.S. in

\footnotetext{
${ }^{30}$ For certain purposes, the FCC has previously characterized rural markets as having fewer than 100 people per square mile. (FCC 2004).

31 If site construction, backhaul, and spectrum acquisition costs do vary by terrain, our estimated factors may not fully capture the effect of terrain on deployment costs.
} 
$2014 .^{32}$ The natural logarithm of the average square miles of service area per cell site in a county for each provider is regressed on terrain variation in the county as well as many other factors that are expected to affect the average land area that is served by a cell site (FCC 2020e, Appx. B, p. 12). To estimate how many more sites must be built per square mile in rougher terrain as compared to flat areas, the estimated model is used to predict the average number of square miles that are covered by a typical site in the following three terrain categories: flat, hilly, and mountainous. ${ }^{33}$ Finally, we use these coverage estimates to calculate an adjustment factor by dividing the estimated service area of a site in a flat area by the estimated service area in each of the other two terrain categories. The results suggest that-relative to the flat terrain category - the hilly terrain category is about 1.5 times more expensive to deploy, while the mountainous terrain category is approximately 2.5-3 times as costly (FCC 2020e, Appx. B, p. 17).

We derive the regression specification based on engineering principles and signal propagation modeling (FCC 2020e, Appx. B, p. 11). One important consideration is how to account properly for differences in mobile data demand across geographic areas. In areas where the network traffic served by a cell site approaches the site's capacity limit, the result is congestion and a degradation in service quality (OBI Technical Paper, No. 1 2010).

We account for the effect of subscriber data demand on the average per-site service area in two ways: First, our flexible functional form allows the effect of terrain to decline as capacity constraints increase by interacting the terrain variable with subscribers per megahertz of spectrum (FCC 2020e, Appx. B, p. 16). Second, we restrict our estimation to more rural counties by estimating the model on sub-samples of counties with population densities less than 100,50 and 20 people per square mile. (FCC 2020e, Appx. B, p. 16) The estimated model for the natural logarithm of the expected average service area per site in county $i$ provider $j$, in Cellular Market Area $k$, and state $m$ is as follows (FCC 2020e, Appx. B, p. 16):

$$
\begin{aligned}
& \ln \left(\text { CoverageAreaPerSite }_{i j k m}\right)=\beta_{0}+\beta_{1} \text { Terrain }_{i j}+\beta_{2} \text { PopDen }_{i} \\
& \quad+\beta_{3} \ln \left(\text { RMDen }_{i}\right)+\beta_{4} \ln \left(\text { EstDen }_{i}\right)+\beta_{5} \ln \left(\text { Income }_{i}\right)+\beta_{6} \ln \left(\text { SubsPerMHz }_{j k}\right) \\
& \quad+\beta_{7} \ln \left(\text { SubsPerMHz }_{j k}\right) \text { XTerrain }_{i j}+\beta_{8} \text { PercAreaLTE }_{i j}+\beta_{9} \text { PercAreaForest }_{i} \\
& +\beta_{10} \text { LowBand }_{i j}+\beta_{11} \text { LowBand }_{i j} \text { XPercAreaForest }_{i}+\beta_{12} \text { LowBand }_{i j} \text { XTerrain }_{i j} \\
& +\beta_{13} \ln \left(\text { DownSpeed }_{i j}\right)+\beta_{14} \text { TowerHeight }_{i j}+\beta_{15} \text { Prov }_{j}+\beta_{16} \text { State }_{m}+\varepsilon_{i j}
\end{aligned}
$$

\footnotetext{
32 We chose the county as our geographic unit of analysis because we do not observe the actual geographic service area of each site. The choice of county minimizes the number of sites with coverage that crosses the geographic (county) boundary while still maintaining necessary terrain variation.

33 The predictions set subscribers per megahertz of deployed spectrum at the 5th percentile to remove all potential capacity constraint issues from our estimated site service areas for each terrain category. Since all adjustment factors are calculated relative to the coverage area of a cell site in flat terrain, only the values of the terrain variable and any variables interacted with terrain affect the estimated adjustment factors. The values of all other variables affect only the level of the predicted coverage area of a cell site in each terrain category.
} 
Table 1 Regression results for entry model (main specification)
Dependent variable $=$ number of entrants

$\begin{array}{ll}\text { Population density } & 0.05 * * * \\ \text { Road mile density } & (0.00) \\ & 0.70 * * * \\ \text { Local GDP density } & (0.04) \\ & 0.04 * * * \\ \log (\text { Income) } & (0.01) \\ & 0.51 * * * \\ \text { \% of land covered by dense clutter } & (0.10) \\ & -0.02 * * * \\ & (0.00)\end{array}$

National providers receiving USF funding

One

Two

$-0.45 * * *$

Regional provider receiving USF funding

$-0.99 * * *$

Observations

28,519

Threshold 1

$-1.33 * *$

(0.42)

Threshold 2

Threshold 3

$1.79 * * *$

Threshold 4

$(0.41)$

Robust standard errors in parentheses; ***p $<0.01, * * p<0.05$, ${ }^{*} p<0.10$

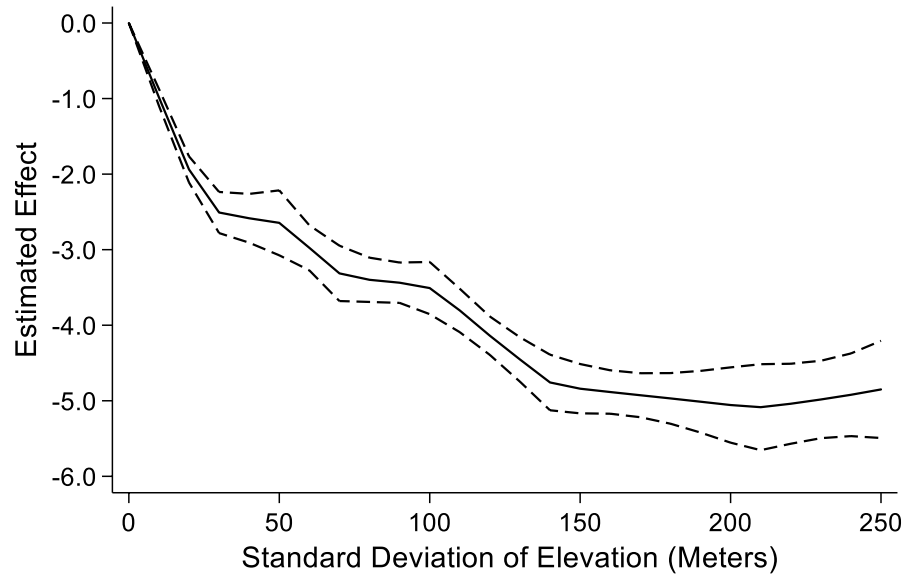

Fig. 1 Effect of terrain on block group attractiveness 
Table 2 Adjustment factor estimates for entry model (baseline specification)

\begin{tabular}{llll}
\hline \multicolumn{4}{l}{ Terrain roughness } \\
\cline { 2 - 4 } & Flat & Hilly & Mountainous \\
\hline Median household income & & & \\
Low & 1.35 & 2.81 & 4.06 \\
& {$[1.25,1.45]$} & {$[2.50,3.12]$} & {$[3.69,4.42]$} \\
Medium & 1.24 & 2.69 & 3.96 \\
& {$[1.18,1.30]$} & {$[2.40,2.98]$} & {$[3.61,4.30]$} \\
High & 1 & 2.40 & 3.67 \\
& & {$[2.14,2.66]$} & {$[3.36,3.98]$} \\
\hline
\end{tabular}

95\% confidence intervals are shown in brackets

The coefficients on nearly all variables are generally consistent with the predictions of wireless network engineering models across a wide range of robustness checks (FCC 2020e, Appx. B, p. 16). As is shown in Table 3, the coefficients on both the terrain variable and the percentage-of-the-county-that-is-forested variable were negative and statistically significant; this implies that the average service area of a site decreases as the terrain becomes more mountainous and forested. Similarly, as the number of subscribers per megahertz of spectrum, density of establishments, road miles, and population increase, the expected average area that is served by a site is expected to decrease. Deploying low-band spectrum was found both to increase the expected average service area of a site and to reduce the impact of terrain and other obstacles on signal propagation (FCC 2020e, Appx. B, p. 16).

\subsubsection{Auction Model and the Adjustment Factor}

Our third model uses auction bidding data from a previous FCC reverse auction of mobile broadband subsidies to provide further estimates of appropriate adjustment factors (FCC 2012a). Economic theory predicts that a higher requested subsidy for a given area in such an auction implies some combination of higher costs to serve the area, lower expected revenue, or the bidder expects less competition from other bidders. To examine the relationship between terrain, local economic conditions, and subsidies that are required to serve uncovered areas, we regress observed bids on area-specific variables that account for differences in expected costs and revenues and potential competition in the auction (FCC 2020e, Appx. B, p. 20). We then use the estimated model to predict the ratio of bid amounts in different categories of terrain while holding all other factors fixed (FCC 2020e, Appx. B, p. 23).

In the Mobility Fund proceeding, the FCC established Auction 901 to distribute Universal Service Funds to providers in exchange for extending mobile broadband service to unserved areas (FCC 2012a). Bidders in the first-price single round sealed-bid auction submitted bids that indicated the subsidy that they would accept to serve all unserved road miles in a geographic area (FCC 2012a). Winning bids 


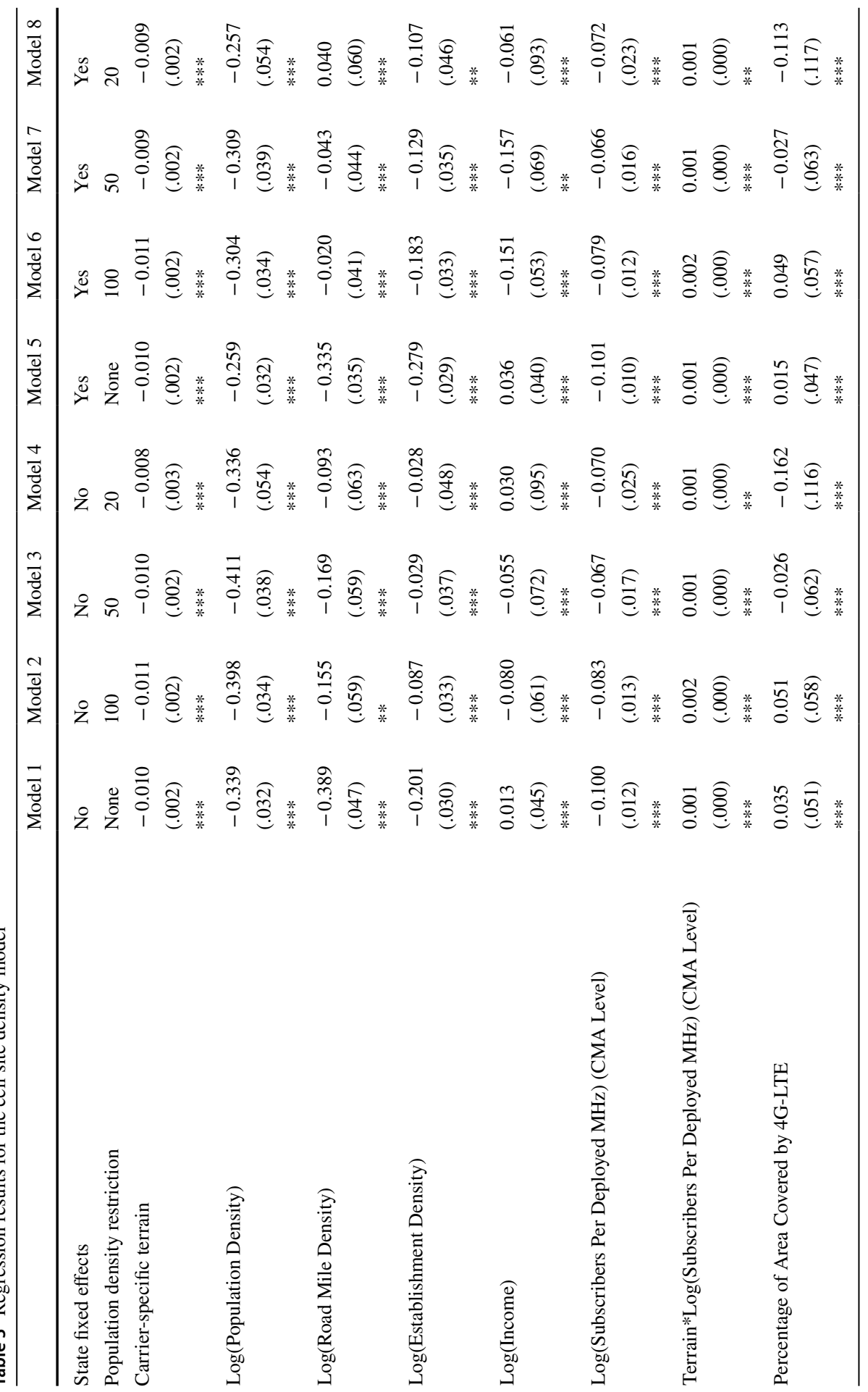




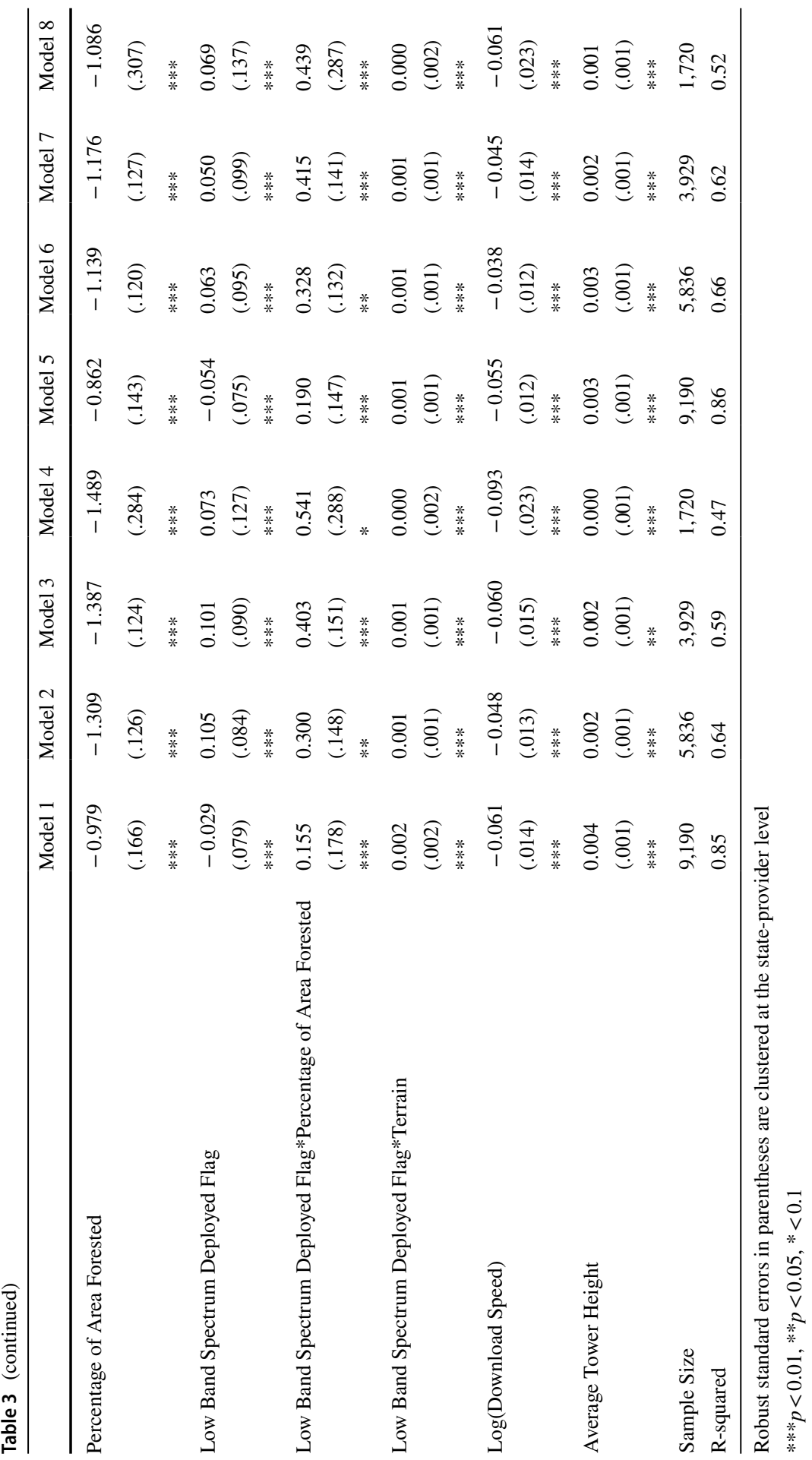


were determined by an algorithm that favored lower bids on a per road mile basis but that also kept total awarded bids within a budget. ${ }^{34}$

We regress the natural logarithm of the dollar per road mile bid (log bids) on expected revenue and cost factors, $X_{i j}$, plus bidder level fixed effects, $\phi_{j}$, where $i$ indicates the geographic area and $j$ indicates the bidder (FCC 2020e, Appx. B, p. 21):

$$
\ln \left(\operatorname{Bid}_{i j}\right)=X_{i j} \beta+\phi_{j}+\varepsilon_{i j}
$$

$X_{i j}$ includes our primary variables of interest - the natural logarithms of terrain roughness and of household median income of the area's Census tract-among other variables that control for expected mobile broadband revenues and costs (FCC 2020e, Appx. B, p. 21). To improve comparability of the observations, we limit the sample to 517 bids in the continental United States in non-tribal areas (FCC 2020e, Appx. B, p. 21). As robustness checks, we further restrict the estimation sample to: (1) the sub-sample of bids that did not default on their bids after the auction; and (2) only winning bids that did not default. In addition, we also calculate two of the variables - the weighted count of providers, and service coverage variables - by two different methods: The first is on an area basis, and the second is on a road mile basis. As a result, six specifications were estimated (FCC 2020e, Appx. B, p. 23).

We present our results for all six specifications in Table 4. Across all specifications, we find a statistically significant positive impact of terrain but a statistically insignificant impact of household median income (FCC 2020e, Appx. B, p. 23). Across all specifications, our terrain measure has an implied elasticity of terrain roughness and subsidy amount between 0.16 and 0.23 (FCC 2020e, Appx. B, p. 23 ). Due to the statistical insignificance of the coefficient on income, we decline to calculate the adjustment based on income. Using the model estimates, we calculate the expected bid ratio by terrain roughness categories holding all other factors fixed (FCC 2020e, Appx. B, p. 23). Our results suggest that hilly areas require 1.6 times the subsidy amount of flat areas, all else equal, while mountainous areas require 1.9 times greater subsidies (FCC 2020e, Appx. B, p. 23).

\section{Inmate Calling Services (ICS)}

In 2003, the FCC was petitioned to investigate alleged anticompetitive practices that result in excessive telephone services rates that are charged to incarcerated individuals held in jails and prisons (FCC 2003). The 2012 Notice of Proposed Rulemaking showed that per-call charges ranged from $\$ 0.50$ to $\$ 3.95$, and per-minute charges ranged from $\$ 0.05$ to $\$ 0.89$ (FCC 2012b). In 2016, more than 2.1 million people

\footnotetext{
34 The algorithm considered the lowest bid in an area to be a tentatively winning bid. The algorithm then ranked the areas in ascending order by their tentatively winning bids on a per-road mile basis. As it went through the ranking, the algorithm awarded subsidies - that were equal to the per-road mile bid times the road mile service requirement - if that item had not been previously assigned and the total requested subsidies did not exceed the Mobility Fund Phase I budget (FCC 2012a).
} 


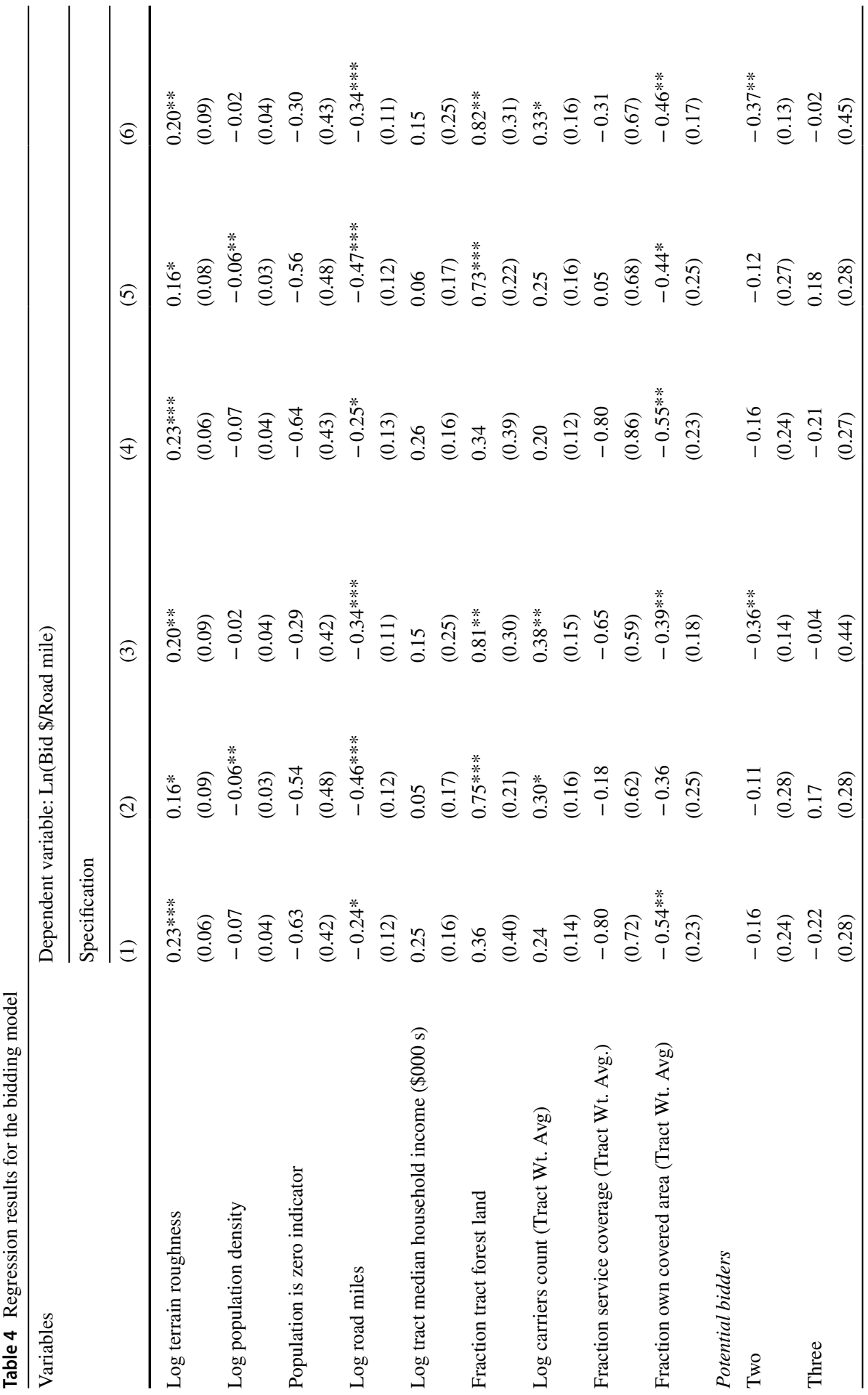




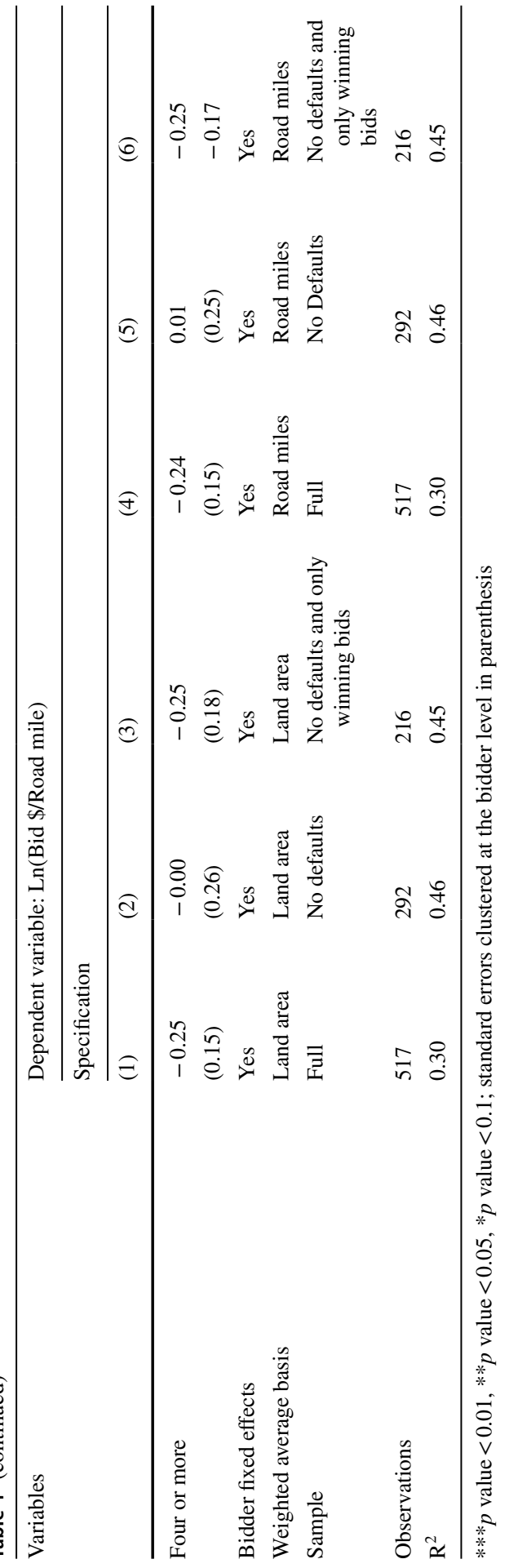


were being held in a correctional facility (DOJ 2018). The high inmate calling rates and ancillary fees not only affect those incarcerated but also impose an undue economic and emotional burden on their families and friends (FCC 2013). Children, in particular, can suffer severe emotional consequences as a result of a parent being incarcerated (Wiltz 2016). Evidence shows that regular phone contact between inmates and their families potentially may provide many benefits, including lower recidivism rates (GAO 2012; FCC 2013).

The FCC has previously imposed caps on interstate ICS. In 2013, the FCC capped rates on an interim basis and adopted a one-time mandatory data collection to guide the process of setting permanent rate caps (FCC 2013). In 2015, the FCC issued an Order that addressed high rates and fees by capping rates for intrastate and interstate ICS and by imposing limits on ancillary service fees that are charged by providers (FCC 2015). The FCC adopted in 2016 an Order on Reconsideration, increasing the rate caps adopted in 2015 (FCC 2016b). In 2016, the DC Circuit Court stayed both the 2015 and 2016 Orders; in 2017, the Court vacated the rate caps in the 2015 Order and remanded certain issues for further proceedings (Court of Appeals, DC Circuit 2017).

In this section, we discuss the FCC's efforts at reforming the ICS marketplace, with an emphasis on the economic analysis that helps to guide policymaking. We start with a brief description of the ICS marketplace. Next, we provide a more indepth description of the FCC's regulatory efforts.

\subsection{The ICS Marketplace}

The provision of ICS differs from that of residential telephony: ICS require security measures that are aimed at preventing individuals from committing crimes while incarcerated. Individuals are typically assigned a limited list of numbers that they can call; the list usually comprises family members, friends, and/or legal counsel. ICS providers' security systems prevent extraneous calls from being placed that may result in the harassment and intimidation of correctional officers, judges, witnesses, and their families. Many facilities now require continuous biometric checks that reduce the frequency of these calls. Other security requirements include giving officers the ability to listen to and record calls, tests of whether a call has been forwarded to another number, and voiceovers that announce the name and location of the caller.

Because of these unique requirements, correctional authorities commonly outsource the provision of ICS to one of several firms that specialize in these services. Typically, a Request-for-Proposals (RFP) is published by a correctional authority, and ICS providers submit bids in response. Correctional authorities then select an ICS provider and award it an exclusive, multi-year ICS contract. Often, the criteria that are used for awarding ICS contracts put considerable weight on the level of site commissions: payments that are made by ICS providers to correctional authorities. As a result, the selection criteria rarely include any consideration of lower ICS rates and fees. 
Site commissions - either lump sum or variable (i.e., paid as a percentage of revenue) - are prevalent in the ICS industry. These payments are widely viewed by the public as kickbacks and can be quite sizable. ${ }^{35}$ In 2013, the FCC reported that variable site commissions range from 20 to $88 \%$ of the gross revenues that are collected by a provider (FCC 2013). While the existence of variable commissions may help to mitigate risk and the effects of asymmetric information between prison authorities and providers, the very high levels of variable commissions that are commonly specified in ICS contracts are likely to distort economic outcomes away from efficiency. Better economic outcomes for providers, correctional authorities, and the public at large could likely be achieved through lower variable commission rates and total commission payments that remain unchanged through increases in the level of fixed commission payments. ${ }^{36}$

The RFP-winning provider has a de facto monopoly for ICS in a detention facility for the duration of the contract (typically, in excess of three years, and often for five or more years). This allows the provider to charge rates that can be well above marginal cost. It also allows providers to charge high fees for ancillary services, such as: the opening and closing of payment accounts; the delivery of paper bills; and depositing money in a payment account. In 2013, the FCC reported that these fees can represent a quite high (up to 38\%) share of all ICS customer charges (FCC 2013).

Historically, the FCC has favored regulatory efforts that help amplify market forces over heavy-handed regulation. However, the market failures in the ICS marketplace stifle competition and result in higher prices and reduced economic efficiency. To fulfill its mandate of promoting the public interest, the FCC has established regulations to limit ICS rates to ensure that just and reasonable rates are accessible to incarcerated individuals and their families and friends. We provide below a summary of the FCC's ICS regulatory actions.

\subsection{Regulatory History}

The First ICS Order concluded that market forces were not operating to promote lower prices and economic efficiency and implemented interim rate caps of $\$ 0.21$ per minute for debit and prepaid calls, and $\$ 0.25$ per minute for collect calls (FCC 2013). Importantly, these caps applied only to calls that crossed state lines. ${ }^{37}$ The First ICS Order also initiated a mandatory data collection that required all ICS providers to submit cost information to the FCC to allow the FCC to establish just and reasonable permanent rate caps. The First ICS Order did not address the legality of

\footnotetext{
35 Prison Policy Initiative, https://www.prisonpolicy.org/blog/2019/02/11/kickbacks-and-commissions/.

36 Variable royalty and concession payments are widespread in several industries (e.g., publishing); however, the variable commission rates in ICS typically are significantly higher than in other industries. Perhaps in recognition of the distortionary effects of variable commissions, several correctional authorities have limited or done away with variable commissions or commissions of any kind (e.g., correction departments in the states of California, Maryland, and South Carolina).

37 Historically, these types of calls represent only about $20 \%$ of the total volume of inmate calling minutes.
} 
site commissions but stated that they were not reasonably related to the provision of ICS (FCC 2013).

The Second ICS Order-based on the data submitted into the record as a result of the 2013 data collection-stipulated that the cost of providing ICS in prisons is typically significantly lower than in jails and made the case that rate caps should vary depending on the type of facility (FCC 2015). ${ }^{38}$ As a result, the FCC adopted three different rates for jails depending on the size of the facilities: $\$ 0.22$ per minute for jails with 1-349 inmates; \$0.16 per minute for jails with 350-999 inmates; and $\$ 0.14$ per minute for jails with 1,000 or more inmates (FCC 2015). For prisons, the facility size was shown to not be a significant determinant of costs, so a flat rate of $\$ 0.11$ per minute was established for all prison calls from these facilities (FCC 2015). The Order also stipulated that the FCC has the authority to regulate intrastate calls from correctional facilities and that the adopted rate caps would apply to all calls, intra- and inter-state (FCC 2015).

Shortly after the adoption of the Second ICS Order, five ICS providers and numerous state and local authorities petitioned the U.S. Court of Appeals for review. The petition challenged the FCC's authority to cap intrastate rates and the exclusion of site commissions as costs of providing ICS. In the case Global Tel*Link v. FCC, the D.C. Circuit agreed with the petitioners that the FCC exceeded its statutory authority by attempting to regulate intrastate calls. ${ }^{39}$ The rates adopted in the Second ICS Order were vacated, and the interim rate caps that were adopted in the First ICS Order are currently in place. The Court also found that site commissions are ICSrelated because they are determined as part and parcel of the contracts between ICS providers and the correctional authorities.

\subsection{Ongoing Work}

The FCC's Office of Economics and Analytics (OEA) and the Wireline Competition Bureau have further analyzed the data that were submitted to the FCC as part of the mandatory data collection that was authorized by the Second ICS Order. ${ }^{40}$ In its Second ICS Order, the FCC requested that each provider submit detailed information for each correctional facility where it provides ICS. The data collection consisted of the characteristics of the facility, the volume of calls and minutes, revenues and costs, and ancillary services. To allow the FCC to examine differences in costs across various types of correctional facilities, providers were asked to report a facility's address, its average inmate population, and whether the facility is a jail or a prison. Providers were asked to classify the number of minutes of calls for a

\footnotetext{
38 The data in the record indicated that individuals who are incarcerated in prisons typically make fewer calls per year, but that calls are on average of greater duration in prisons than in jails. Prisons typically incarcerate individuals for longer periods than is true for jails, which typically confine individuals who await trial and those serving short sentences.

39 See GlobalTel *Link v. FCC, 866 F.3d 397 (D.C. Cir. 2017).

40 We note that, because of the confidential nature of the data that were collected, this subsection is limited to a general discussion of the information we collected and the methodologies we used.
} 
given year by call jurisdiction (intrastate, interstate, and international) and by the method of payment (collect, debit, or prepaid). Similarly, providers were asked to classify the number of calls by the method of payment. The FCC also requested detailed financial information such as revenues by method of payment and the total ICS costs. Finally, the FCC requested information that was related to the provision of ancillary services, including: the number of times that each service was provided; the per-occurrence charge; and the sum of ancillary revenues collected.

The FCC analyzed these data to determine whether certain characteristics of ICS contracts - such as the Average Daily Population (ADP), the type of facilities included in a contract (prisons or jails), and geography (i.e., state and rurality) of the facilities - have a meaningful association with contract costs. If these variables can be shown to have a meaningful association with costs, the FCC would be able to set appropriate interstate caps for correctional facilities based on these variables.

OEA staff used a statistical method called adaptive Lasso (Tibshirani 1996) to explore variables that might be good predictors of contract costs per minute and might predict whether a given contract is one of the top $5 \%$ of contracts by costs per minute. The unit of observation for our analysis was an ICS contract. ${ }^{41}$ The contract variables that we considered in our analysis were as follows:

- The identity of the ICS provider;

- The state in which ICS facilities that are covered by a contract are located;

- The Census division and region in which contracts are located;

- The type of facility (prison or jail);

- An indicator for joint contracts (i.e., contracts for which an ICS provider subcontracts with another ICS provider);

- ADP;

- $\mathrm{ADP}$ bins $(\mathrm{ADP} \leq 25, \mathrm{ADP} \leq 50, \mathrm{ADP} \leq 100, \mathrm{ADP} \leq 250, \quad \mathrm{ADP} \leq 500$, $\mathrm{ADP} \leq 1000, \mathrm{ADP} \leq 5000)$;

- Rurality of the facilities covered by the contract, for example, whether the facilities that are covered by the contract were all located in a census block that is designated rural, or an urban cluster, or urban, by the Census Bureau; and

- Various combinations (or interactions) between the above variables.

Since the matter is still ongoing before the Commission, we cannot elaborate on the results of our analysis beyond those that were presented in the Fourth Further Notice of Proposed Rulemaking that was adopted by the FCC in August 2020, where we found that a provider's identity and state were the main predictors of cost per minute and of high-cost contracts (FCC 2020p).

\footnotetext{
41 An ICS contract may cover more than one facility, but several features of the data that are less meaningful, or are unavailable, at the facility level.
} 


\section{Telehealth and COVID-19}

In early 2020, an unprecedented viral pandemic quickly spread around the world, wreaking havoc on both physical and economic health. As of late September 2020, there were nearly 32 million cases around the world, and more than 972,000 people had lost their lives (Johns Hopkins 2020). The expansive governmental and societal response has included widespread business and school closings, physical distancing, and other preventative measures. Signs of economic displacement emerged as the pandemic ushered in significant negative externalities and uncertainties. The COVID-19 pandemic meant economists and other officials across government agencies had to implement new policies quickly to respond to significant negative shocks to public health and the economy. Government agencies stepped in with fiscal, monetary, and other types of economic relief.

Telecommunications has played a special role in supporting economies during the pandemic by enabling remote work, commerce, and education. The United States' telecommunications networks were well-positioned to respond as millions moved to telework and e-learning. At the same time, however, the FCC recognized that many Americans were in need of help to cope with the consequences of COVID-19. Economists and other staff from OEA played a critical part in the agency's pandemic response. They took action to improve telehealth and thus reduce the externalities of COVID-19 by reducing the need for sick patients to leave their homes and put others at risk. OEA helped the agency to design and implement its telehealth program as efficiently as possible, given the urgency brought about by the pandemic.

On March 13, Chairman Pai called on broadband and telephone service providers to "Keep Americans Connected" to ensure that Americans would not lose their broadband or telephone connectivity as a result of these exceptional circumstances (FCC 2020h). Chairman Pai asked broadband and telephone service providers, and trade associations, to pledge to not terminate service, to waive late fees, and to open Wi-Fi hotspots. Chairman Pai also urged them to expand low-income broadband programs, relax data usage limits, and promote remote learning and telehealth. More than 800 companies and associations signed the Chairman's pledge to Keep Americans Connected, and many have gone above and beyond the pledge (FCC 2020i).

The FCC itself took numerous actions to aid Americans affected by the COVID19 pandemic (FCC 2020h). These actions include, for example:

1. Granting providers additional spectrum to support increased broadband usage;

2. Granting spectrum to promote connectivity on Tribal Reservations;

3. Helping Puerto Rico and the U.S. Virgin Islands stay connected;

4. Supporting rural health care providers, school, and libraries by waiving gift rules;

5. Increasing rural health care funding;

6. Waiving lifeline program rules to help low-income consumers;

7. Providing regulatory relief to Zoom and WebEx to support the need for video conferencing;

8. Enabling interpreters to work from home to maintain relay services for the disability community; and 
9. Providing consumers with needed information about scams and tips for optimizing home networks.

One of the most critical efforts of the FCC's pandemic response is the COVID19 Telehealth Program: On March 27, 2020, the President signed the Coronavirus Aid, Relief, and Economic Security (CARES) Act into law (CARES Act 2020). ${ }^{42}$ Among other things, the CARES Act provided \$200 million to the FCC to support health care providers in the fight against the COVID-19 pandemic. The Act directed that the FCC should expend funds "to prevent, prepare for, and respond to coronavirus, domestically or internationally, including to support efforts of health care providers to address coronavirus by providing telecommunications services, information services, and devices necessary to enable the provision of telehealth services." (CARES Act 2020).

Standing up a new program to responsibly distribute assistance in a crisis is an intensive undertaking. When Congress directed the FCC to spend \$200 million to support telehealth, OEA economists and data professionals devoted significant efforts to planning and data. They helped to build the new systems and processes necessary to take in and review applications, make awards, and distribute funds. Having OEA as part of the planning and implementation contributed to efficiencies in processes and outcomes. They helped direct limited resources to hardest hit areas in order to maximize the benefits of the program. (FCC 2020j).

The benefits of telehealth services have been known for some time. For example, Jennett al. (2003) note the main benefits of telehealth: increased access to health services; cost-effectiveness; enhanced educational opportunities; improved health outcomes; better quality of care; better quality of life; and enhanced social support. Subsequently, Whitacre (2011) attempted to quantify the potential economic benefits of rural telemedicine adoption in four states. He estimated the savings due to reduced travel expenses, reductions in lost wages, and hospital cost savings.

Schadelbauer (2017) also focused on rural telehealth, and noted the non-quantifiable benefits of telemedicine, including access to specialists, timeliness, comfort, removal of transportation barriers, benefits to providers (access to specialists), and improved outcomes for patients. ${ }^{43}$ In addition, Schadelbauer noted quantifiable benefits of telemedicine including reduced transportation costs, reduced lost wages, reduced hospital costs (due to access to remote specialists), and increased local lab/ pharmacy revenues. A 2020 study by the Veterans Administration concluded that, for many patients, video health care is equivalent to or preferred to in-person care (Slightam et al. 2020).

\footnotetext{
${ }^{42}$ The CARES Act appropriates \$200 million to the Commission "to support efforts of health care providers to address coronavirus by providing telecommunications services, information services, and devices necessary to enable the provision of telehealth services" during the pendency of the COVID-19 pandemic.

${ }^{43}$ This study updated and expanded the Whitacre (2011) study to cover all 50 states and demonstrated substantial benefits.
} 
During the COVID-19 pandemic, another benefit of telehealth service has been seen: a reduction in the spread of disease. Virtual care keeps patients at home, where they cannot spread germs to others or be exposed; it also aids in prompt detection and early isolation and makes contacting doctors easier, bettering chances for speedy recovery (Virk 2020). Several barriers to telehealth services existed prior to the COVID-19 pandemic, including limited Medicare coverage, legal and regulatory challenges, and broadband access challenges (AHA 2020).

Numerous barriers to telehealth have been lowered to allow many patients to see their health care providers from the safety of their homes. In March 2020, the U.S. Department of Health and Human Services announced that it would waive potential penalties for Health Insurance Portability and Accountability Act of 1996 (HIPAA) violations against health care providers providing telehealth services during the COVID-19 nationwide public health emergency (HHS 2020). Medicare has begun to support in-home and nursing home telehealth services. Private insurers have launched coverage of telehealth services (CCHPCA 2020a), and many states have taken action to remove barriers to telehealth by waiving licensure requirements and expanding coverage (CCHPCA 2020b). The American Medical Association provides a summary of state directives to expand telemedicine services in response to COVID-19 (AMA 2020).

On March 31, 2020, the FCC adopted a Report and Order launching its COVID19 Telehealth Program (FCC 2020j). Through the COVID-19 Telehealth Program, the FCC is helping healthcare providers purchase telecommunications, broadband connectivity, and devices necessary for providing telehealth services. Upon adoption of this order, Chairman Pai said, “Our nation's healthcare providers need us more than ever, and we at the FCC are answering the call. With the adoption of the \$200 million COVID-19 Telehealth Program, the FCC can now take immediate steps to provide funding so that more patients can be treated at home, freeing up valuable hospital beds for those who most need them and reducing the risk of exposure to the virus." (FCC 2020k).

On April 13, the FCC began accepting COVID-19 Telehealth Program applications. Applications from eligible healthcare providers were processed on a rolling basis. Application review focused on areas hit hardest by coronavirus, and the FCC considered a variety of other factors, including funding requested.

On April 16, the FCC announced the first set of approved COVID-19 Telehealth Program applications, providing funding to health care providers in some of the hardest hit areas in the United States (FCC 20201). The FCC continued to review applications and made awards on a rolling basis until the $\$ 200$ million of funding that was authorized by Congress was exhausted. On July 8, the FCC announced the final set of approved applications (FCC 2020m). Applicants that were awarded funding are able to seek reimbursement from the FCC for eligible services and devices.

With the help of program funding, healthcare providers are able to purchase equipment, devices, and services for use with telehealth, including computers, tablets, headphones, webcams, remote monitoring equipment, software licenses, and telehealth stations. They also are able to purchase needed network upgrades, mobile hotspots, and internet access. The services and equipment that have been acquired 
support a range of telehealth services, including: patient testing and screening; voice and video consultations; and remote patient monitoring.

The program helps healthcare providers to continue offering primary care, emergency, intensive care, mental and behavioral health, and dental services while limiting the spread of the virus and reducing patient and provider exposure. For example, some program awardees proposed to use funding to transition their nonclinical workforce to remote settings, reduce in-person visits, and enable healthcare professionals who have been exposed to the virus to continue seeing patients while self-isolating. Others planned to use funds for equipment to use to minimize personnel exposure while performing essential medical procedures. including surgery and intensive care visits. COVID-19 telehealth program awardees are also targeting some of the most vulnerable, at-risk populations in the nation, such as the elderly, the chronically ill, those with mental health and substance abuse challenges, lowincome communities, and rural and tribal areas. The complete list of funded applications is publicly available (FCC 2020n). In all, the FCC approved 539 applications including more than three thousand health care locations across 49 states plus the District of Columbia and Guam.

\section{Conclusion}

As explained in this essay, over the past year, FCC economists helped develop efficient mechanisms for making available more flexible-use spectrum for the deployment of advanced broadband technologies. In addition, FCC economists developed two new universal service funding mechanisms that aim to close the digital broadband divide; and, through careful analysis of firm cost data, contributed to a renewed effort by the Commission to develop price caps for interstate calls on prison inmate calling services. Finally, FCC economists also contributed to the Commission's extensive response to COVID-19.

Acknowledgements We thank all of the economists at the Federal Communications Commission who contributed to the proceedings that are discussed in this essay. We note that the opinions expressed herein are those of the authors and do not represent those of the Federal Communications Commission or any other members of its staff, or of Indiana University or any other members of its staff.

\section{References}

American Hospital Association (AHA). (2020). Fact Sheet: Telehealth. Retrieved from https://www.aha. org/factsheet/telehealth.

American Medical Association (AMA) Advocacy Resource Center. (2020). TELEMEDICINE: Summary of state directives to expand telemedicine services in response to COVID-19. Retrieved from https:// www.ama-assn.org/system/files/2020-04/telemedicine-state-orders-directives-chart.pdf.

Bresnahan, T. F., \& Reiss, P. C. (1991). Entry and competition in concentrated markets. Journal of Political Economy, 99(5), 977-1009.

Campbell Scientific Inc. (2016). The link budget and fade margin. Retrieved from https://s.campbellsc i.com/documents/us/technical-papers/link-budget.pdf.

CARES Act. (2020). Pub. L. No 116-136, 134 Stat. 281. 
Center for Connected Health Policy (CCHPCA). (2020a). COVID-19 Telehealth Coverage Policies. Retrieved from https:/www.cchpca.org/resources/covid-19-telehealth-coverage-policies.

Center for Connected Health Policy (CCHPCA). (2020b). COVID-19 Related State Actions. Retrieved from https://www.cchpca.org/resources/covid-19-related-state-actions.

Court of Appeals, DC Circuit. (2017). Global Tel v. Federal Communications Commission. Retrieved from https://www.cadc.uscourts.gov/internet/opinions.nsf/C62A026B396DD4C78525813E004F3B C5/\$file/15-1461-1679364.pdf

Department of Justice, Bureau of Justice Statistics. (2018). Correctional populations in the United States, 2016. Retrieved from https://www.bjs.gov/content/pub/pdf/cpus16.pdf.

Federal Communications Commission. (2003). Implementation of the pay telephone reclassification and compensation provisions of the telecommunications act of 1996. Petition of Martha Wright et al. for Rulemaking (or Petition to Address Referral Issues in Pending Rulemaking), CC Docket No. 96-128 (filed Nov. 3, 2003).

Federal Communications Commission. (2004). Facilitating the provision of spectrum-based services to rural areas and promoting opportunities for rural telephone companies to provide spectrum-based services et al., Report and Order and Further Notice of Proposed Rulemaking. Retrieved from https ://www.fcc.gov/document/facilitating-provision-spectrum-based-services-rural-areas-and.

Federal Communications Commission. (2011). Connect America Fund et al., WC Docket No. 10-90 et al., Report and Order and Further Notice of Proposed Rulemaking. Retrieved from https://www. fcc.gov/document/fcc-releases-connect-america-fund-order-reforms-usficc-broadband.

Federal Communications Commission. (2012a). Mobility fund phase $i$ auction scheduled for september 27, 2012, notice and filing requirements and other procedures for auction 901. Retrieved from https ://www.fcc.gov/document/mobility-fund-auction-procedures-and-filing-requirements.

Federal Communications Commission. (2012b). Rates for interstate inmate calling services, WC Docket No. 12-375, Notice of Proposed Rulemaking. Retrieved from https://www.fcc.gov/document/rates -interstate-inmate-calling-services- 0 .

Federal Communications Commission. (2013). rates for interstate inmate calling services, WC Docket No. 12-375, Report and Order and Further Notice of Proposed Rulemaking. Retrieved from https:// www.fcc.gov/document/fcc-releases-order-reducing-high-inmate-calling-rates.

Federal Communications Commission. (2015). Rates for interstate inmate calling services, WC Docket 12-375, Second Report and Order and Third Further Notice of Proposed Rulemaking. Retrieved from https://ecfsapi.fcc.gov/file/60001333338.pdf.

Federal Communications Commission. (2016a). Use of spectrum bands above 24 GHZ for mobile radio services, et. al., GN Docket No. 14-177, Report and Order and Further Notice of Proposed Rulemaking. Retrieved from https://www.fcc.gov/document/spectrum-frontiers-ro-and-fnprm.

Federal Communications Commission. (2016b). Rates for interstate inmate calling services, WC Docket No. 12-375, Order on Reconsideration. Retrieved from https://www.fcc.gov/document/fcc-releasesinmate-calling-services-order-reconsideration.

Federal Communications Commission. (2017a). Strategic plan 2018-2022. Retrieved from https://www. fcc.gov/about/strategic-plans-budget.

Federal Communications Commission. (2017b). Use of spectrum bands above $24 \mathrm{GHz}$ for mobile radio services, GN Docket No. 14-177, Second Report and Order, Second Further Notice of Proposed Rulemaking, Order on Reconsideration, and Memorandum Opinion and Order. Retrieved from https ://www.fcc.gov/document/fcc-takes-next-steps-facilitating-spectrum-frontiers-spectrum.

Federal Communications Commission. (2018a). FCC adopts first communications marketplace report. Retrieved from https://www.fcc.gov/document/fcc-adopts-first-consolidated-communications-marke tplace-report- 0 .

Federal Communications Commission. (2018b). Use of spectrum bands above $24 \mathrm{GHz}$ For mobile radio services, et al., Third Report and Order, Memorandum Opinion and Order, and Third Further Notice of Proposed Rulemaking. Retrieved from https://www.fcc.gov/upper-microwave-flexible-use-servi ce-umfus-releases.

Federal Communications Commission. (2018c). Use of Spectrum Bands Above 24 GHz For Mobile Radio Services, et al., Fourth Report and Order. Retrieved from https://www.fcc.gov/upper-microwaveflexible-use-service-umfus-releases, https://docs.fcc.gov/public/attachments/FCC-18-180A1.pdf.

Federal Communications Commission. (2018d). Connect America fund phase ii auction (Auction 903) closes; Winning bidders announced; FCC Form 683 Due October 15, 2018, AU Docket No. 17-182, WC Docket No. 10-90, Public Notice. Retrieved from https://docs.fcc.gov/public/attac hments/DA-18-887A1.pdf. 
Federal Communications Commission. (2019a). Transforming the $2.5 \mathrm{GHz}$ Band. WT Docket No. 18-120. Report and Order. Retrieved from https://www.fcc.gov/document/fcc-transforms-25-ghzband-5g-services-0.

Federal Communications Commission. (2019b). Auction of $28 \mathrm{GHz}$ upper microwave flexible use service licenses for next-generation wireless services closes, AU Docket No. 18-85, Public Notice. Retrieved from https://www.fcc.gov/document/auction-101-closing-public-notice.

Federal Communications Commission. (2019c). Auction of $24 \mathrm{GHz}$ upper microwave flexible use service licenses closes, AU Docket No. 18-85, Public Notice. Retrieved from https://www.fcc.gov/docum ent/auction-102-closing-public-notice.

Federal Communications Commission. (2020a). Expanding flexible use of the 3.7 to $4.2 \mathrm{GHz}$ band. GN Docket No. 18-122. Report and Order and Order of Proposed Modification. Retrieved from https:// www.fcc.gov/document/fcc-expands-flexible-use-c-band-5g-0.

Federal Communications Commission. (2020b). FCC initiatives. Retrieved from https://www.fcc.gov/ about-fcc/fcc-initiatives.

Federal Communications Commission. (2020c). Rural digital opportunity fund, connect America Fund, WC Docket No. 19-126, WC Docket No. 10-90, Report and Order. Retrieved from https://www.fcc. gov/document/fcc-launches-20-billion-rural-digital-opportunity-fund-0.

Federal Communications Commission. (2020d). Establishing a $5 G$ fund for rural America, universal service reform-mobility fund, GN Docket No. 20-32, WT Docket No. 10-208 (closed). Retrieved from https://www.fcc.gov/document/fcc-proposes-5g-fund-rural-america-0.

Federal Communications Commission. (2020e). Office of economics and analytics and wireline competition bureau seek comment on adjustment factor values for the 5G fund, GN Docket No. 20-32. Retrieved from https://www.fcc.gov/document/bureau-seek-comment-adjustment-factor-value s-5g-fund.

Federal Communications Commission. (2020f). Rural digital opportunity fund phase $i$ auction schedule for october 29, 2020. AU Docket No. 20-34. WC Docket No. 19-126, WC Docket No. 10-90. Retrieved from https://www.fcc.gov/document/fcc-adopts-procedures-rural-digital-opportunit y-fund-auction- 0 .

Federal Communications Commission. (2020g). Incentive auction of upper microwave flexible use service licenses in the upper $37 \mathrm{GHz}, 39 \mathrm{GHz}$ and $47 \mathrm{GHz}$ bands for next-generation wireless services Closes. AU Docket No. 19-59. Retrieved from https://www.fcc.gov/document/fcc-concludes-large st-ever-spectrum-auction.

Federal Communications Commission. (2020h). Keep Americans connected. Retrieved from https:// www.fcc.gov/keep-americans-connected.

Federal Communications Commission. (2020i). Companies have gone above and beyond the call to keep Americans Connected during pandemic. Retrieved from https://www.fcc.gov/companies-pledgingkeep-americans-connected-during-pandemic-go-above-and-beyond-call.

Federal Communications Commission. (2020j). Promoting Telehealth for low-income consumers COVID-19 Telehealth program, Report and Order. Retrieved from https://docs.fcc.gov/public/attac hments/FCC-20-44A1.pdf.

Federal Communications Commission. (2020k). FCC adopts $\$ 200$ million COVID-19 Telehealth program. Retrieved from https://docs.fcc.gov/public/attachments/DOC-363498A1.pdf.

Federal Communications Commission. (20201). FCC approves first set of Covid-19 Telehealth program applications. Retrieved from https://docs.fcc.gov/public/attachments/DOC-363770A1.pdf .

Federal Communications Commission. (2020m). FCC approves final set of COVID-19 Telehealth program applications. Retrieved from https://docs.fcc.gov/public/attachments/DOC-365417A1.pdf.

Federal Communications Commission. (2020n). Final list of COVID-19 Telehealth program awardees. Retrieved from https://www.fcc.gov/sites/default/files/covid-19-telehealth-program-recipients.pdf.

Federal Communications Commission. (2020o). Rural digital opportunity fund Phase 1 auction updated eligible areas. Retrieved from https://www.fcc.gov/document/rural-digital-opportunity-fund-phase -i-auction-updated-eligible-areas.

Federal Communications Commission. (2020p). FCC seeks to reduce rates and charges for inmate calling services. Retrieved from https://www.fcc.gov/document/fcc-seeks-reduce-rates-and-chargesinmate-calling-services.

Government Accountability Office, Bureau of Prisons. (2012). Growing inmate crowding negatively affects inmates, staff, and infrastructure. Retrieved from https://www.gao.gov/assets/650/64812 3.pdf. 
U.S. Department of Health and Human Services (HHS). (2020). OCR announces notification of enforcement discretion for Telehealth remote communications during the COVID-19 nationwide public health emergency. Retrieved from https://www.hhs.gov/about/news/2020/03/17/ocr-announces-notif ication-of-enforcement-discretion-for-telehealth-remote-communications-during-the-covid-19.html.

Jakes, W.C. (1993). Microwave mobile communications. 126-28.

Jennett, P. A., Affleck Hall, L., Hailey, D., et al. (2003). The Socio-economic impact of Telehealth: A systematic review. Journal of Telemedicine and Telecare, 9(6), 311-320.

Johns Hopkins University of Medicine. (2020). Coronavirus Resource Center, COVID-19 Case Tracker. Retrieved from https://coronavirus.jhu.edu/.

Omnibus Broadband Initiative (OBI). (2010). The broadband availability gap: OBI technical paper no. 1. Retrieved from https://www.broadband.gov/plan/broadband-working-reports-technical-papers.html.

Rappaport, T.S. (2002). Wireless communications principles and practice (pp. 141-43).

Schadelbauer, R. (2017). Anticipating economic returns of Rural Telehealth. NTCA the rural broadband association white paper.

Slightam, C., Gregory, A., Hu, J., et al. (2020). Patient perceptions of video visits using veteran affairs telehealth tablets: survey study. Journal of Medical Internet Research, 22(4), e15682.

Tibshirani, R. (1996). Regression Shrinkage and Selection via the Lasso. Journal of the Royal Statistical Society Series B (Methodological), 58(1), 267-288.

Virk, S. (2020). Coronavirus and telemedicine: How it can help practices and patients with communicable diseases. Medical Economics.

Wiltz, Teresa. (2016). Having a parent behind bars costs children, states. Retrieved from https://www. pewtrusts.org/en/research-and-analysis/blogs/stateline/2016/05/24/having-a-parent-behind-barscosts-children-states

Whitacre, B. (2011). Estimating the economic impact of telemedicine in a rural community. Agricultural and Resource Economics Review 40/2.

Publisher's Note Springer Nature remains neutral with regard to jurisdictional claims in published maps and institutional affiliations.

\title{
Affiliations
}

\section{Allison Baker ${ }^{2} \cdot$ Patrick Brogan ${ }^{2}$. Octavian Carare ${ }^{2} \cdot$ Nicholas Copeland $^{2}$. Patrick DeGraba ${ }^{2}$. Steven Kauffman ${ }^{2}$. Paul Lafontaine ${ }^{2}$. Catherine Matraves ${ }^{2}$. Jeffrey Prince ${ }^{1,2}$ D Sean Sullivan ${ }^{2} \cdot$ Patrick Sun $^{2} \cdot$ Emily Talaga $^{2}$}

\author{
Allison Baker \\ Allison.Baker@fcc.gov \\ Patrick Brogan \\ Patrick.Brogan@fcc.gov \\ Octavian Carare \\ Octavian.Carare@fcc.gov \\ Nicholas Copeland \\ Nicholas.Copeland@fcc.gov \\ Patrick DeGraba \\ Patrick.DeGraba@fcc.gov \\ Steven Kauffman \\ Steven.Kauffman@fcc.gov \\ Paul Lafontaine \\ Paul.LaFontaine@fcc.gov
}


Catherine Matraves

Catherine.Matraves@fcc.gov

Sean Sullivan

Sean.Sullivan@fcc.gov

Patrick Sun

Patrick.Sun@fcc.gov

Emily Talaga

Emily.Talaga@fcc.gov

1 Kelley School of Business, Indiana University, Bloomington, IN, USA

2 Federal Communications Commission, 445 12th St SW, Washington, DC 20554, USA 